\title{
Workability and mechanical properties of ultrafine cement based grout for structural rehabilitation: A parametric study on the partial replacement with SCMs
}

\author{
Md Shamsuddoha*, Götz Hüsken, Wolfram Schmidt, Hans-Carsten Kühne, and Matthias Baeßler
}

Bundesanstalt für Materialforschung und -prüfung (BAM), Unter den Eichen 87, 12205 Berlin, Germany

\begin{abstract}
Grouting is a universal repair and strengthening technique, which is constantly used for structural remediation of concrete components, trenches, mine subsidence, dam joints, restoration of masonry structures, and geological stabilizations. Having an extremely small particle size of only few microns, ultrafine cements are ideal for grouting applications due to their superior permeability and compressive strength properties of the hardened cement paste compared to that of the less-expensive, but coarser ordinary Portland cements. Supplementary cementitious materials (SCMs) are often used to replace ultrafine cement in order to modify certain properties and to reduce costs. The aim of this experimental study is to investigate the effect of three supplementary materials: microsilica (MS), fly ash (FA), and metakaolin (MK) on the workability, and mechanical properties of an ultrafine cement based grout with a constant water-binder ratio and constant superplasticizer content. Maximum percentages of replacement with ultrafine cement were $6 \%$ by volume of cement for MS and $16 \%$ for FA, and MK. In general, results suggest that the workability is improved by addition of FA, whereas is reduced, when modified with MS and MK. The compressive strength of grout after cement replacement remains comparable to that of pure cement grout. However, there is a tendency of the MS to positively affect the compressive strength opposite to FA, whereas flexural strength is positively affected by FA. Based on the results, it is evident that grouts with Hägerman cone flow more than $500 \mathrm{~mm}$ and compressive strength of more than $90 \mathrm{MPa}$ after 28 days can be produced.
\end{abstract}

\section{Introduction}

Grouts are ideal candidates for rehabilitation of concrete and composite structures. Besides, grouts are widely used for tunnelling, soil stabilization, and foundation technologies both onshore and offshore sites. Application of such products pose considerable challenges due to specific properties during mixing, pumping, spreading or injection, and physical properties during service conditions. The rheological properties and stability are thus important in determining the penetrability of such cement grouts [1]. A higher water content usually provides certain favourable rheological properties, however may not be suitable for some other requirements and thus requires optimization [2-5]. A combination of suitable ingredients is necessary to achieve those desired properties.

Generally, there are two most commonly sorted grout systems: cement grouts and chemical grouts, which are defined by the type of binders used in them. Chemical grouts are primarily epoxy-based, polyurethane-based, and other polymer grouts. A cement based grout is sometimes preferred due to compatibility and environmental superiority. However, finer cement is required to achieve better penetrability. Ultrafine cements are ideal for structural applications due to superior permeability and strength properties of the hardened cement paste compared to that of the less expensive, but coarser ordinary Portland cements $[6,7]$. This type of cement has an extremely small particle size of only few microns. The interaction of these finer particles affects properties of the final product $[8,9]$. Most of these ultrafine cements are quite similar in their physical properties as conventional Portland cements. When compared to chemical grouts, ultrafine cement grouts offer an economical and efficient alternative. The financial advantage can further enhanced when the ultrafine cement is partially replaced with supplementary cementitious materials (SCMs). Microsilica (MS), fly ash (FA), and metakaolin (MK) are commonly used pozzolanic materials [10]. However, their inclusion can affect various properties. Besides, high range water reducing admixtures are sometimes necessary to attain suitable properties [11]. Since three variables are involved, a parametric study is essential to carry out a detailed study to attain suitable properties from an optimum range of SCMs.

This parametric study is aimed to determine the range of ingredients that can produce a structural grout using ultrafine cement as primary binder. Slump flow is determined as an indicator of workability. Whereas

* Corresponding author: Md.Shamsuddoha@bam.de 
compressive and flexural strength were determined to assess physical properties. Statistical mix design approach is used and results are presented using contour response surfaces. The general trend of inclusion of the supplementary materials is identified. Grout systems suitable for structural rehabilitation could be formulated based on the properties investigated. A typical example of overlapping the response surfaces for determining ingredients for certain properties is also discussed.

\section{Experimental Program and materials}

The Design of Experiments (DOE) is an efficient statistical procedure for planning experiments so that a series of data obtained can be analysed. The parameters are in the form of inputs and outputs. This procedure uses the experimental data to develop an empirical model linking those outputs and inputs. The simplest DOE can be one factor design, where one parameter is changed and other are kept constant. However, in case of larger variables, this process can results in increased number of tests, which eventually increase testing and decision time along with associated costs. Being first devised in 1960, Box-Behnken is one of the experimental design techniques that investigate the influence of different variables on the outcome of a controlled experiment [12]. This Box-Behnken design methodology is adopted in this study over typical Central Composite Design (CCD) due to the fact that it requires less number of test runs to observe the trend in output with reasonable statistical accuracy. The second degree graduating polynomial that best represents the relation is given as Equation 1, where $x_{i}$ refers to the input factors which influence the response, $y$. The first coefficient, $a_{x}$ represents the combination of the mean and the provision for an error adjustment. The rest of coefficients in the forms of $a_{i}$ denote individual and combined effects from three variables.

$$
\begin{aligned}
& y=a_{x}+a_{1} x_{1}+a_{2} x_{2}+a_{3} x_{3}+a_{4} x_{1}^{2}+a_{5} x_{2}^{2}+ \\
& a_{6} x_{3}^{2}+a_{7} x_{1} x_{2}+a_{8} x_{1} x_{3}+a_{9} x_{2} x_{3}
\end{aligned}
$$

Solution of these response equations was carried out using regression analysis with an aim to minimize the $c h i$ square. The reason for using these analogy was to achieve the best fit predictions, since errors were minimized in comparison to individual data points. A common way of representing experimental design outcomes is the response surface methodology (RSM). RSM provides an ease of observations among the variables and combined effects spanning the entire experimental region of interest. This method was actually developed by Box and Wilson in 1951 to aid the improvement of manufacturing processes in the chemical industry [13]. A graphical and statistical tool; Origin software [14] was used to contour plots and carryout analysis of variances in this study.

A micro-fine hydraulic binder was used in this study. The cement complied (with the exception of setting time) with the requirements given by EN 197-1 for CEM I 52.5 R LA SR. It has a particle size distribution, where 95 percent of the materials is less than $12 \mu \mathrm{m}$ and BET specific surface of $2200 \mathrm{~m}^{2} / \mathrm{kg}$. Three supplementary cementitious materials were used in this study: silica fume / microsilica (MS), Class F fly ash (FA), and metakaolin (MK). The physical properties of SCMs are also given in Table 1.

Table 1. Physical properties of cement and SCMs

\begin{tabular}{ccccc}
\hline \multirow{2}{*}{ Properties } & \multicolumn{4}{c}{ Ingredients } \\
\cline { 2 - 5 } & Cement & MS & FA & MK \\
\hline Specific & 3.140 & 2.207 & 2.320 & 2.593 \\
Density & 12 & 35 & 150 & 20 \\
D $95(\mu \mathrm{m})$ & 12 &
\end{tabular}

A total 15 test runs are required for three factors considered in this study. The contents corresponds to coded values specified by Box and Behnken [12]. Table 2 shows the test matrix and ingredients. MS, FA, and MK contents are kept to $0-6 \%, 0-16 \%$, and $0-16 \%$, respectively. It can be seen that $-1,0$, and +1 represent the corresponding lowest, medium, and maximum values, respectively. Cement was replaced with SCM contents by volume. An additional mixture 16 is also shown, which represents the mixture with neat cement only and can be used as a reference for comparison.

Mixing was carried out using an intensive mortar mixer. The dried powder contents were first mixed for 1 minute at $400 \mathrm{rpm}$. Then, water and half of the plasticizer were added at a time and mixed for 1 minute at $400 \mathrm{rpm}$. Afterward rest half of the plasticizer is added and mixed for another minute at the same speed. A break of 1.5 minutes in mixing is taken for scrapping the mixing container. The mix is then continued for 1 minute at 400 rpm, 2 minutes at $800 \mathrm{rpm}$.

Table 2. Test matrix

\begin{tabular}{cccccccc}
\hline Mix & Coded values & \multicolumn{5}{c}{ Volume (\%) } \\
\cline { 3 - 8 } & & & & Cement & MS & FA & MK \\
& & & & & $x_{1}$ & $x_{2}$ & $x_{3}$ \\
\cline { 3 - 8 } 1 & -1 & -1 & 0 & 92 & 0 & 0 & 8 \\
2 & 1 & -1 & 0 & 86 & 6 & 0 & 8 \\
3 & -1 & 1 & 0 & 76 & 0 & 16 & 8 \\
4 & 1 & 1 & 0 & 70 & 6 & 16 & 8 \\
5 & -1 & 0 & -1 & 92 & 0 & 8 & 0 \\
6 & 1 & 0 & -1 & 86 & 6 & 8 & 0 \\
7 & -1 & 0 & 1 & 76 & 0 & 8 & 16 \\
8 & 1 & 0 & 1 & 70 & 6 & 8 & 16 \\
9 & 0 & -1 & -1 & 97 & 3 & 0 & 0 \\
10 & 0 & 1 & -1 & 81 & 3 & 16 & 0 \\
11 & 0 & -1 & 1 & 81 & 3 & 0 & 16 \\
12 & 0 & 1 & 1 & 65 & 3 & 16 & 16 \\
13 & 0 & 0 & 0 & 81 & 3 & 8 & 8 \\
14 & 0 & 0 & 0 & 81 & 3 & 8 & 8 \\
15 & 0 & 0 & 0 & 81 & 3 & 8 & 8 \\
16 & - & - & - & 100 & 0 & 0 & 0 \\
\hline
\end{tabular}

A Polycarboxylatether based superplasticizer (SP) was used. It is a brown coloured liquid with a specific density of $1060 \mathrm{~kg} / \mathrm{m}^{3}$ and $\mathrm{pH}$ of 6.5 . This plasticizer conforms to DIN EN 934-2 [15]. An initial test program 
was performed to determine the saturation point of the SP content in relation to neat cement. Flow diameter and rheological parameters showed a saturation point of $3.0 \%$ by weight of cement, below and beyond which properties showed adverse trend. Hence, a SP content of $3.0 \%$ by weight of $100 \%$ neat cement was used further in this study for all mixes. Since a finer cement was used, it was assumed that the superplasticizer had enough charges for the binders including SCMs. Based on the desire to achieve a low initial apparent viscosity value, it was decided to use this dosage by mass of dry neat cement and to apply the same dosage to all cement suspensions for reasons of uniformity and preparation simplicity, without optimizing the dosage for each specific suspension. The basis of uniform SP dosage regardless of suspension was also adopted by other researchers [3, 16, 17]. Such high SP dosage is not uncommon in literature [11], where up to $3.5 \%$ SP was used. Besides there were no drastic retardation was observed in the mixtures even with the highest SCMs.

Primary properties of a grout system can be classified into two groups: fresh properties and hardened properties. In this study, workability was determined at fresh state, whereas compressive and flexural strengths were determined at hardened state. Paste flow was measured using Hägerman cone conforming to DIN EN 1015-3 [18]. Slump was determined 10 minutes after the beginning of mixing for all the grout. No vibration was used due to the fact that grouts should inherently have a self-compacting behaviour. Compression and flexural tests were carried out conforming BS EN 196-1 [19], where 40x40x160 mm prismatic samples were used. Six samples were tested for each reported compressive strength, whereas a set of three samples were tested for flexural strength. Prisms were cured at submerged condition at $23^{\circ} \mathrm{C}$ for 28 days. Fig. 1 shows tests are being carried out.

\section{Experimental results and discussion}

The summary of test results obtained is given in Table 3 . The results show ranges of slump flow, compressive strength, and flexural strength to be $503-610 \mathrm{~mm}, 89-$ $123 \mathrm{MPa}$, and 3.0 to $13.5 \mathrm{MPa}$, respectively. Mixture with $3 \% \mathrm{MS}$ and $16 \%$ FA has the highest slump, mixture with only 3\% MS has the highest compressive strength, and mixture with $6 \% \mathrm{MS}$ and $8 \% \mathrm{FA}$ has the highest flexural strength. The reference grout mixture (\#16) with neat cement only has a slump of $568 \mathrm{~mm}$, and compressive and flexural strength of $104 \mathrm{MPa}$, and 6.2 MPa, respectively. Comparing with reference values it can be seen that some of the mixtures have the potential to achieve equal or better properties. However, it is essential to observe effects of SCMs on individual properties, which is difficult to conduct from the values of Table 3 alone.

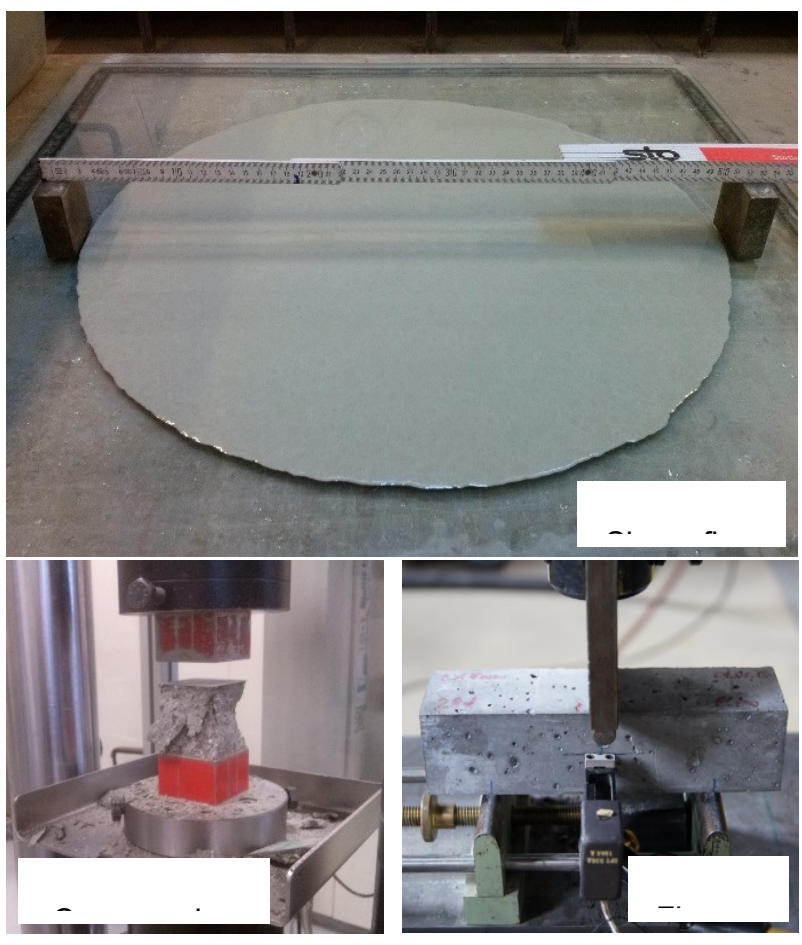

Fig. 1. Paste flow and mechanical tests

Table 3. Summary of test results

\begin{tabular}{cccc}
\hline Mix & $\begin{array}{c}\text { Slump } \\
(\mathrm{mm})\end{array}$ & $\begin{array}{c}\text { Comp. Strength } \\
(\mathrm{MPa})\end{array}$ & $\begin{array}{c}\text { Flex. Strength } \\
(\mathrm{MPa})\end{array}$ \\
\hline 1 & 518 & 119 & 5.8 \\
2 & 503 & 117 & 5.1 \\
3 & 555 & 100 & 3.2 \\
4 & 553 & 102 & 2.6 \\
5 & 577 & 114 & 9.2 \\
6 & 570 & 117 & 13.5 \\
7 & 528 & 109 & 4.2 \\
8 & 538 & 98 & 3.0 \\
9 & 567 & 123 & 4.6 \\
10 & 610 & 103 & 11.0 \\
11 & 501 & 114 & 4.4 \\
12 & 540 & 89 & 3.0 \\
13 & 520 & 110 & 3.0 \\
14 & 518 & 110 & 3.3 \\
15 & 524 & 109 & 5.1 \\
16 & 568 & 104 & 6.2 \\
\hline
\end{tabular}

These results are analysed and statistical models were developed. Regression analysis was carried out and constants mentioned in Equation 1 were determined and outlined in Table 4. Analysis of variance (ANOVA) was also carried out. The summary of ANOVA analysis between experimental and predicted values is also given at the lower part of Table 4. The models show considerable accuracy with predicted models.

The response surface produced for workability is given in Fig. 2. The results suggest that the slump diameter increases with an increase in FA. This trend align with the argument with the analysis of 
morphological nature of fly ash, which suggested that fly ash with smaller particles reduced the filling water and had stronger lubricating role in presence of superplasticizer [20]. Furthermore, the lower specific surface of the fly ash as well as a lower presence of ettringite being formed due to the reduced amount of set retarder is likely to cause an excess of SP polymers that maintain better workability over the course of time. However, workability decreases for increased MK up to $12 \%$. Beyond which there is slight increase in slump. When compared to $0 \%$ and $6 \%$, in general, MS marginally reduced the slump diameter.

Table 4. Statistical models and analysis of variance

\begin{tabular}{ccccc}
\hline & & \multicolumn{3}{c}{ Models } \\
\cline { 2 - 5 } & & $y_{\text {slump }}$ & $y_{\text {comp }}$ & $y_{\text {flex }}$ \\
\hline \multirow{6}{*}{ Constants } & 574.071 & 120.897 & 7.917 \\
& $a_{1}$ & -6.5994 & -0.3094 & 0.0339 \\
& $a_{2}$ & 0.7896 & -0.8243 & 0.1302 \\
& $a_{3}$ & -10.7286 & 0.2826 & -0.7605 \\
& $a_{4}$ & 0.1343 & 0.0439 & 0.0045 \\
& $a_{5}$ & 0.1847 & -0.1457 & -0.0512 \\
& $a_{6}$ & -0.0119 & -0.0264 & -0.0161 \\
& $a_{7}$ & 0.5694 & 0.1312 & 0.06 \\
& $a_{8}$ & 0.0971 & -0.0209 & -0.0031 \\
& $a_{9}$ & 0.4299 & -0.0226 & 0.0428 \\
& $R^{2}$ & 0.9647 & 0.981 & 0.7966 \\
ANOVA & $F$ & $6.2 \times 10^{-6}$ & $4.0 \times 10^{-6}$ & 0.0202 \\
& $F_{\text {crit }}$ & 4.196 & 4.196 & 4.196 \\
\hline
\end{tabular}

The workability loss can be assumed to be induced by the morphology of the MK as well as the high specific surface, causing that SP cannot become effective despite being adsorbed. MS marginally reduces the slump diameter, which is presumably owed to the high specific surface that reduces the free water dramatically as well as attracts SP in the presence of cations from the pore solution. The effects of metakaolin and slilica fume on workability were also verified elsewhere [21]. Besides, considering the fact that the superplasticizer content is constant, this trend is also expected since water demand increases and workability reduces with increasing microsilica content $[22,23]$.

The effect of SCMs on the compressive strength is shown in Fig. 3. In general, strength increases with increasing MS. This trend was also reported earlier [23]. The response surfaces suggest that strength decreases with increasing FA. This effect is more pronounced for FA at low MS content. Reduction in compressive strength was also found when cement was replaced by high volume FA more than $30 \%$ [24]. Besides, a combination of MS $(10 \%)$ with FA resulted in higher strength in that study.
The compressive strength usually decreases, when MK content is increased. It was seen that increase in MK content resulted in an increase in compressive strength, however up to an optimum level, beyond which strength reduced [25]. It is to be noted that lowest compressive strength of $89 \mathrm{MPa}$ was recorded, when the highest SCM content $(35 \%)$ was added. Moreover, whatever the MS content is, a strength of $100 \mathrm{MPa}$ can be achieved as long as MK content is kept at less than 5\%.
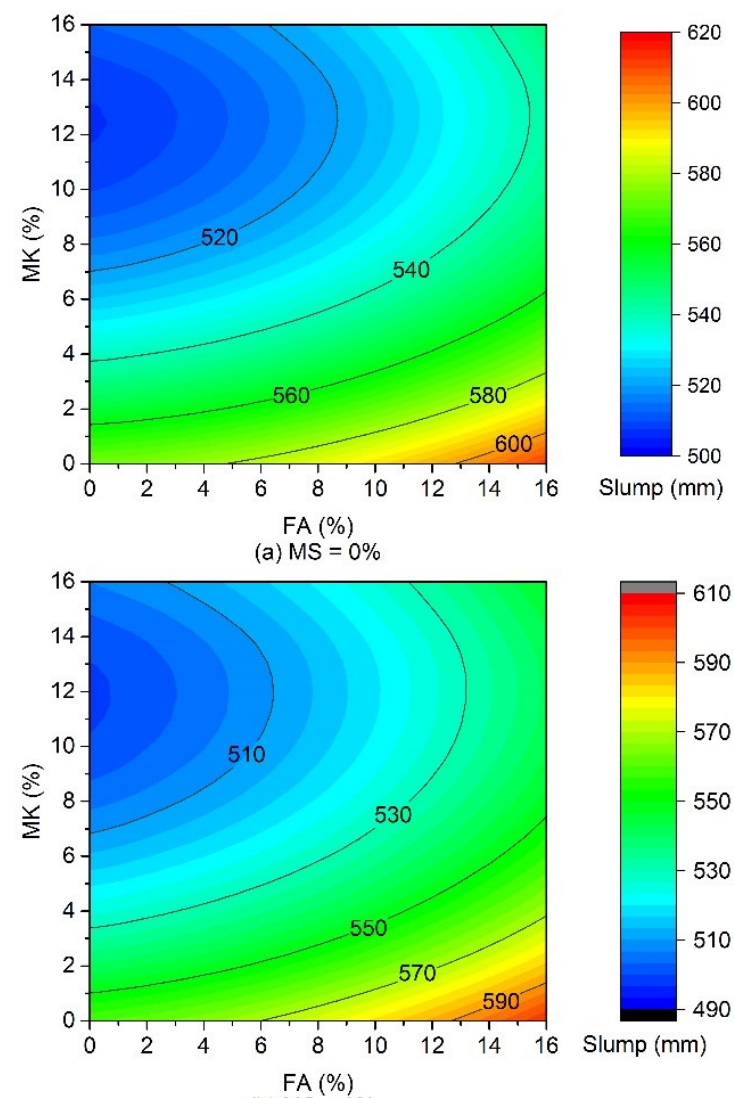

(b) $M S=3 \%$

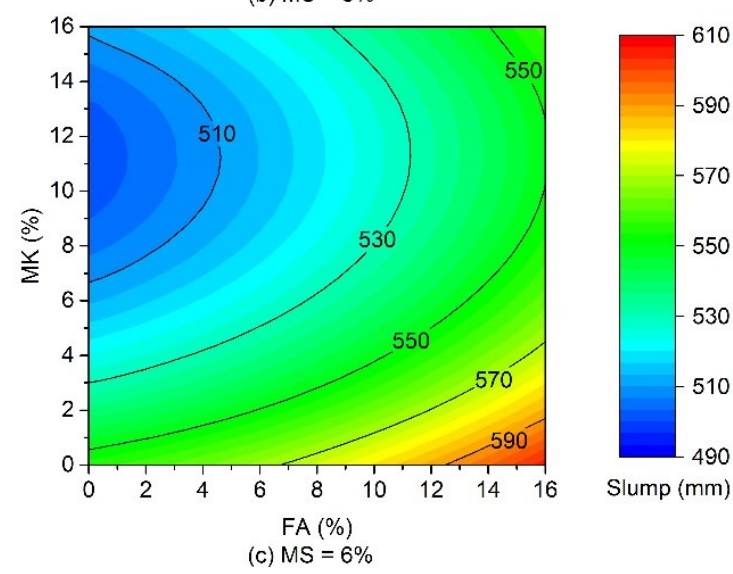

Fig. 2. Response surface for slump flow

Flexural strength is positively affected by MS as shown in Fig. 4. FA content is found to have negligible effect on flexural strength. Increase in MK content reduces the strength. Previous study on mortars also suggested that bending strength is reduced or remained steady when replaced with metakaolin [26]. It is to be noted that there is a low-strength zone near about $10 \%$ 
MK, beyond which MK may marginally increase the strength at low FA content.

In general, it is evident that SCMs can generate similar and even superior properties compared to neat cement grout. Based on the results obtained from this study an evaluation can be carried out in relation to industry practices, previous researches, and existing literature.

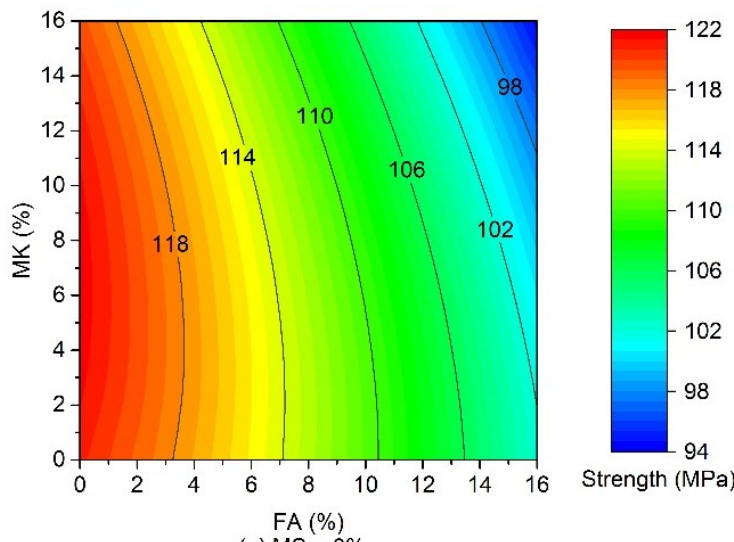

(a) $\mathrm{MS}=0 \%$

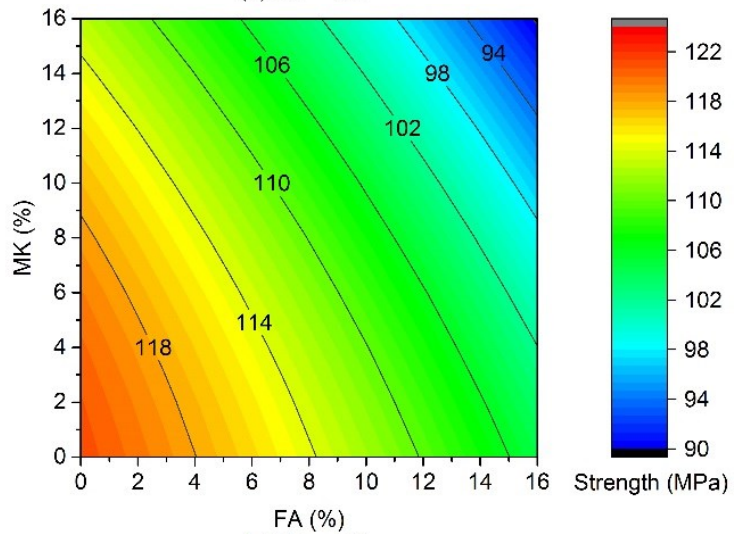

(b) $\mathrm{MS}=3 \%$

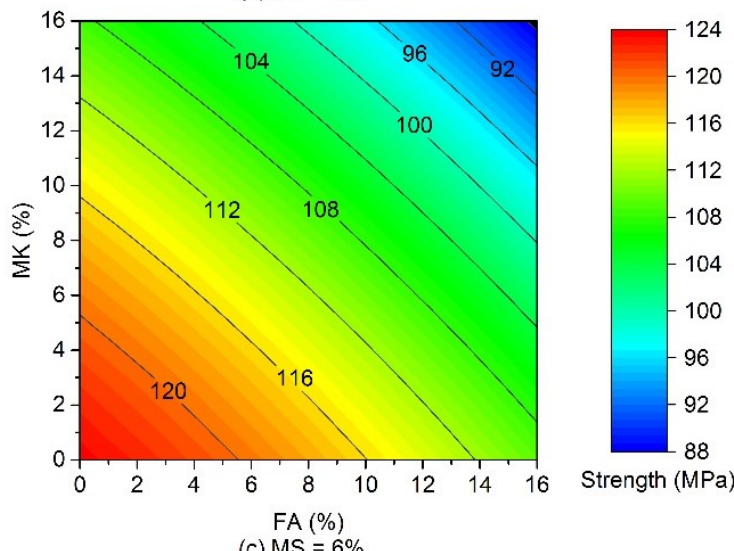

(c) MS $=6 \%$

Fig. 3. Response surface for compressive strength

A slump flow range of $298-465 \mathrm{~mm}$ was reported while optimization of self-compacting grouts for repair purposes [17], whereas a minimum slump of $500 \mathrm{~mm}$ is found in this study. According to DIN EN 1504-3 guide specifications for compressive and flexural strengths of repair materials for Class R4 structural repair is set to be $\geq 45 \mathrm{MPa}$, and $\geq 8 \mathrm{MPa}$, respectively [27]. The minimum compressive strength for the grouts in this study were 89 $\mathrm{MPa}$, which align with the guideline. Moreover, the compressive strength to be $\geq 85 \mathrm{MPa}$, which is set by International Concrete Repair Institute [28]. A flexural strength range of $3.0-13.5 \mathrm{MPa}$ can be achieved in this study. Results from this study suggests that a flexural strength $\geq 8 \mathrm{MPa}$ is also achievable, when a lower metakaolin content is maintained depending on microsilica content.

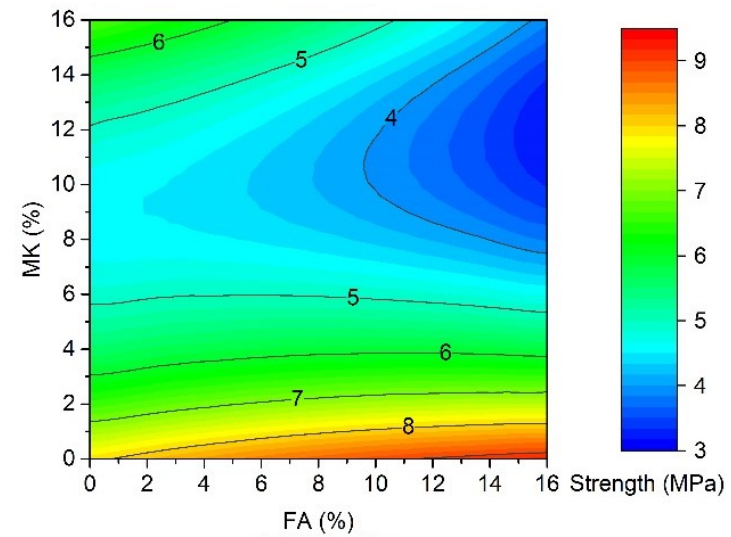

(a) $M S=0 \%$

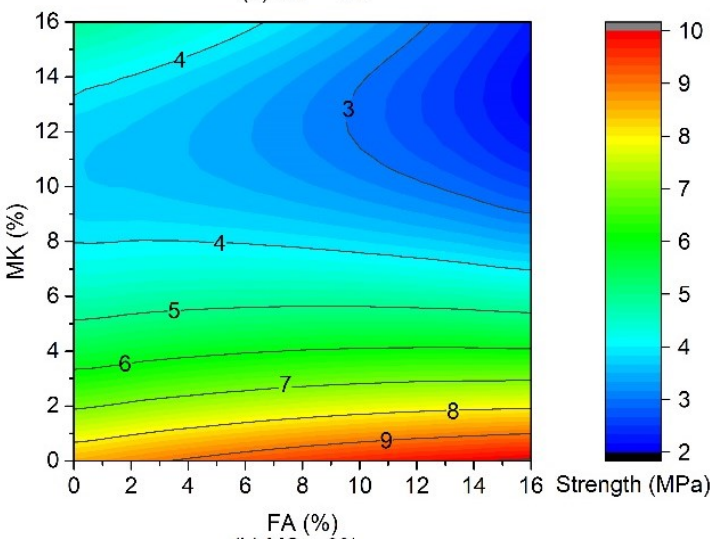
(b) $\mathrm{MS}=3 \%$

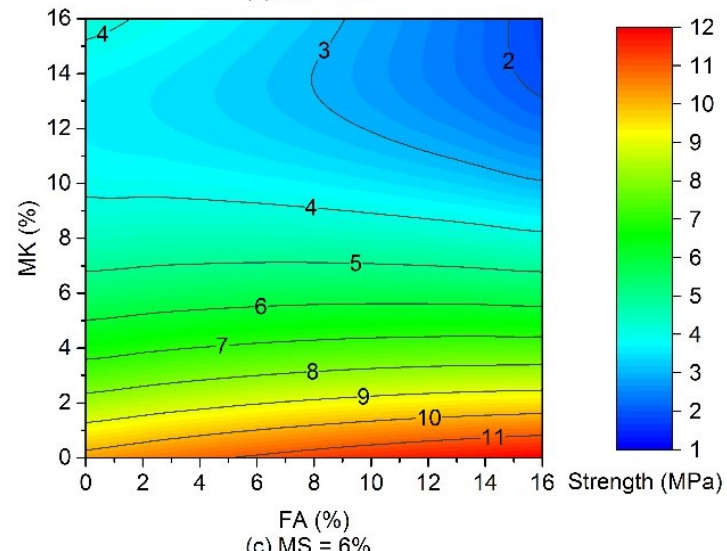

Fig. 4. Response surface for flexural strength

A typical example of interpretation of these trends can be given in Fig. 5. A combination of desired properties of $550 \mathrm{~mm}$ slump, $100 \mathrm{MPa}$ compressive strength, and 8 $\mathrm{MPa}$ flexural strength is chosen in light of the previously discussed guidelines containing $3 \%$ microsilica as a median content. The shaded areas are the recommended zone for the specified set of properties. The lowest densely shaded area is the target contents of ingredients. It can be seen that fly ash provides a much larger 
flexibility in contents compared to metakaolin, which is almost leaning towards zero. Considering the fact that a repair grout should be more workable during application, microsilica and fly ash can be varied within the mix design to achieve desirable properties. Similar selection can be carried out for any other set of given properties.

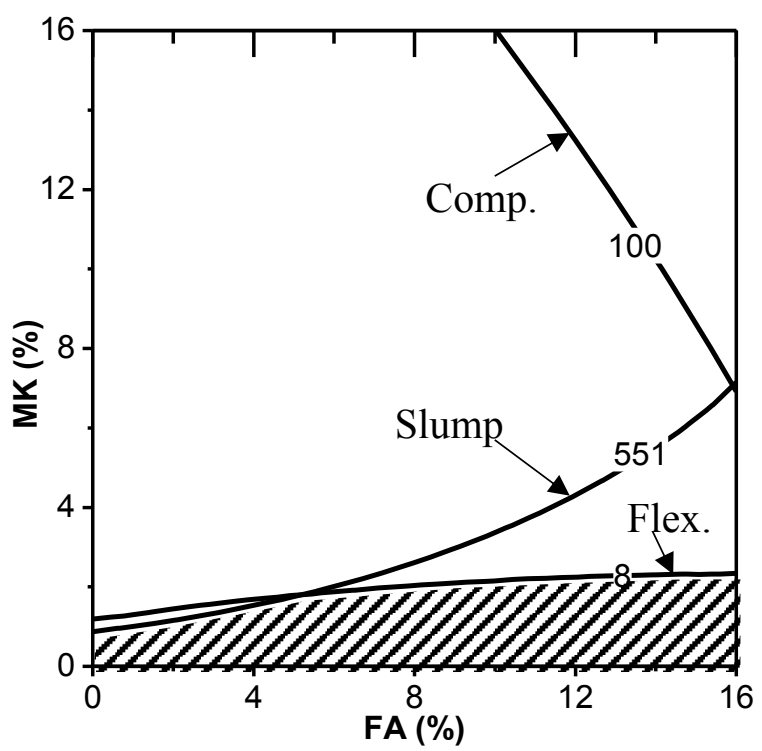

Fig. 5. Typical interaction of properties for optimization

\section{Conclusions}

A series of mix design was formulated and grout products were tested for slump flow, compressive and flexural strength as a parametric study to characterise the effect of replacement by three SCMs: microsilica (MS), fly ash (FA), and metakaolin (MK) with ultrafine cement. A slump flow diameter of $500-600 \mathrm{~mm}$ is achieved. The flow increased with increasing fly ash content. Compressive strength ranges from about $90-125 \mathrm{MPa}$. An increase in microsilica results in increase in compressive strength. Irrespective of microsilica content, a strength of $100 \mathrm{MPa}$ is achievable as long as metakaolin content is kept at a minimum. A flexural strength range of about 3.0 - $13.5 \mathrm{MPa}$ is found, where microsilica positively affected the strength. In general, grouts with comparable properties to that of the neat cement grout is viable.

The workability and mechanical properties of the grouts will aid to understand the behaviour of the grouts in relation to corresponding SCMs. However, the selection of SCM contents should be based on the performance requirement of the rehabilitation in which the grout is going to be used. Besides, further rheological and hardened properties need to be carried out to determine the suitability of the grout in in-situ conditions.

This study was part of LeBeWind project of the Federal Institute for Materials Research and Testing (BAM), Berlin, Germany.

\section{References}

1. U. Håkansson, L. Hässler and H. Stille, Tunnelling and Underground Space Technology 7 (4), 453-458 (1992).

2. A. Bras and F. M. A. Henriques, Construction and Building Materials 26 (1), 135-144 (2012).

3. A. Bras, R. Gião, V. Lúcio and C. Chastre, Cement and Concrete Composites 37, 185-195 (2013).

4. L. G. Baltazar, F. M. A. Henriques and F. Jorne, Construction and Building Materials 35, 838-845 (2012).

5. M. Sonebi, M. Lachemi and K. M. A. Hossain, Construction and Building Materials 38, 126-138 (2013).

6. J. Mirza, K. Saleh, M.-A. Langevin, S. Mirza, M. A. R. Bhutta and M. M. Tahir, Construction and Building Materials 47, 1145-1153 (2013).

7. S. Hu, X. Guan and Q. Ding, Cement and Concrete Research 32 (12), 1871-1875 (2002).

8. D. P. Bentz, E. J. Garboczi, C. J. Haecker and O. M. Jensen, Cement and Concrete Research 29 (10), 1663 1671 (1999).

9. Z. D. Rong, W. Sun, H. J. Xiao and W. Wang, Construction and Building Materials 51, 446-450 (2014).

10. K. H. Obla, C. L. Lobo and H. Kim, (NRMCA Concrete InFocus Magazine, 2012).

11. C. A. Anagnostopoulos, Construction and Building Materials 50, 162-168 (2014).

12. G. E. P. Box and D. W. Behnken, Technometrics 2 (4), 455-475 (1960).

13. A. Dean and D. Voss, Design and Analysis of Experiments. (Springer-Verlag, New York, 1999).

14. Origin, (OriginLab, USA, 2016).

15. Deutsches Institut für Normung e. V., EN 934-2 (Berlin, 2012).

16. I. A. Pantazopoulos, I. N. Markou, D. N. Christodoulou, A. I. Droudakis, D. K. Atmatzidis, S. K. Antiohos and E. Chaniotakis, Cement and Concrete Composites 34 (5), 593-603 (2012).

17. B. Felekoğlu, Construction and Building Materials 22 (4), 660-667 (2008).

18. Deutsches Institut für Normung e. V., DIN EN 1015-3 (Berlin, 2007).

19. European Committee for Standardization, BS EN 1961:2005 (2005).

20. A. Wang, C. Zhang and W. Sun, Cement and Concrete Research 33 (12), 2023-2029 (2003).

21. D. Jian-Tong and L. Zongjin, Materials Journal 99 (4) (2002).

22. E. J. Sellevold and F. F. Radjy, Special Publication 79 (1983).

23. A. Allahverdi and S. Salem, Ceramics-Silikáty 54 (1), 65-71 (2010). 
24. H. Yazıc1, Construction and Building Materials 22 (4), 456-462 (2008).

25. R. Siddique and J. Klaus, Applied Clay Science 43 (3), 392-400 (2009).

26. L. Courard, A. Darimont, M. Schouterden, F. Ferauche, X. Willem and R. Degeimbre, Cement and Concrete Research 33 (9), 1473-1479 (2003).

27. Deutsches Institut für Normung e. V., 1504-3:2015 (Berlin, 2015).

28. ICRI Committee 320, (International Concrete Repair Institute, Rosemont, IL, 2015). 